\title{
EL CORCHO UNA ESTRUCTURA QUE CONSERVA EL MEJOR SABOR DEL VINO
}

\author{
Nurt Heidy Gaitán Becerra \\ Escuela de Negocios, Gestión y Sostenibilidad \\ Programa de Especialización en Gestión Empresarial \\ Especialista en Gestión Empresarial \\ hgatianb21@gmail.com \\ Sandra Beatriz Torres Torres \\ Escuela de Negocios, Gestión y Sostenibilidad \\ Programa de Especialización en Gestión Empresarial \\ Especialista en Gestión Empresarial \\ sanbetoto@yahoo.com
}

\section{Resumen}

El mundo fascinante del corcho jamás conocido como uno de los conservantes de los sin números de sabores de los vinos, permitiendo atesorar sus propiedades originales, las cuales llegan a los paladares de los altos catadores con un alto grado de exquisitez, así como los ajenos del vino que en su desconocimiento no magnifican la importancia de la participación de esta estructura, que no solo permite que liquido no se salga de su empaque, conteniendo la presión dentro de la botella, sino que le da el toque original como un acompañante natural del vino.

Por esto, el propósito del presente artículo es dar a conocer su importancia y aspectos más relevantes, como son los comerciales y ambientales; y en general, aportarle a cada lector más información desde su gusto personal por el gran universo del vino, tomando como referencia la Corticeira Amorím, S.G.P.S. S.A, una de las más importantes empresas productoras de corcho en Chile, quienes nos permitieron conocer el proceso de producción de este importante producto.

Palabras clave: innovación, biodiversidad, corcho. 


\section{"La preparación y transformación del corcho son la más perfecta expresión de la íntima relación entre el hombre y la naturaleza y de la forma en la que el uso consciente de los recursos naturales es la base del Desarrollo Sostenible." Américo Amorim}

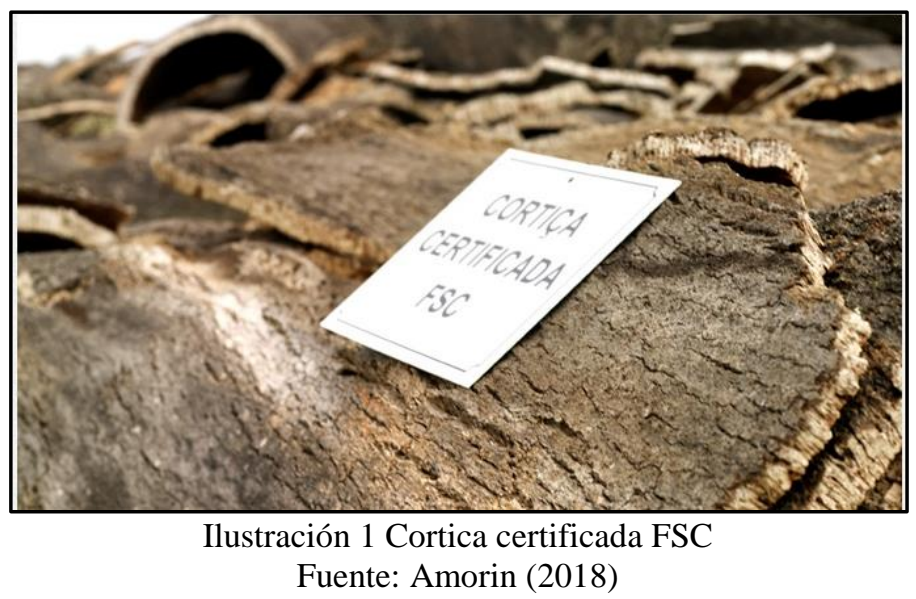

\section{Introducción.}

En el presente artículo se analizará la importancia del corcho en la industria vinícola de Chile. Con este propósito es importante estudiar el valor de la industria del vino en la economía chilena, siendo uno de los sectores más productivos y que van de la mano de este producto.

Iniciemos conociendo la participación de la industria del vino durante el año 2017 en la economía de este país:

El diario El Mostrador en su edición del 7 de febrero de 2018, publicó lo siguiente sobre la industria del vino en Chile:

La historia cultural de Chile está integrada por el vino, es por ello por lo que la industria es un sector de gran dinamismo en la economía chilena, en términos de producción, exportación y generación de empleos, así como las nuevas variedades viníferas, desarrollo de productos de calidad y colocación de mercados nuevos especializados (Comisión Nacional de Investigación Científica y Tecnológica, 2007). Las exportaciones del vino ocupan el quinto lugar después del cobre, el molibdeno, el salmón y la celulosa. Chile ocupa el cuarto lugar dentro de los exportadores a nivel mundial, en primer lugar, se encuentra Italia, luego Francia y España. (Año 2015)

En datos suministrados por la Asociación de Vinos de Chile, el balance para el año 2017 arrojas cifras positivas en correlación con el año inmediatamente anterior, ya que esta tuvo un crecimiento del $3.7 \%$, cuya mayor representación la presenta en el vino embotellado, mayor crecimiento desde el año 2010.cabe destacar que la estrategia planteada para el 2025 es: 
Aumentar la demanda, la competitividad y el precio del vino chileno en el extranjero, se logró superar los objetivos propuestos de crecimiento anual en los envíos de vino embotellado, de $3 \%$ y $5 \%$ respectivamente.

Mario Pablo Silva, presidente de Vinos de Chile, afirma: "nuestro objetivo es consolidarnos como el productor número uno de vinos Premium, sustentables y diversos del mundo, promoviendo la denominación de origen y contribuyendo al desarrollo del sector". Al respecto es conveniente decir, que su plan concreto y sustentable, cuyo propósito es conseguir posición en los vinos Premium, a través del aumento en precio promedio e incrementar la penetración en este mercado (USF60 FOB/caja y más). Sus mercados principales son: China, Estados Unidos Brasil, Canadá y Reino Unido.

Páginas del: El banco central (año 2017) y Santander trade portal (año 2017), suministra la información sobe los indicadores económicos en Chile

Teniendo en cuenta uno de los indicadores más importantes en la macroeconomía, se tuvieron en cuenta como punto de partida: el PIB de Chile del año 2017 el cual fue de 24.537 US ((Int. PPA \$ per capital) con un crecimiento del 1.5\% en relación con el año inmediatamente anterior. En diciembre del año 2017, el sector de la industria del vino generó 100.000 empleos directos y el sector de la agricultura, donde pertenece la industria del vino, tuvo una participación del $4.3 \%$ del PIB.

El análisis da como resultado la importancia y participación de la industria del vino en la economía chilena, y esto demuestra que si esta industria crece, causa un efecto directamente proporcional en la industria del corcho, la cual crecerá en la misma proporción, por ser uno de los insumos más importantes del vino.

En la primera parte, se participará una breve historia del corcho, su importancia como acompañante del vino, procedencia, los principales países productores y su participación y el interés de éstos por mantener una producción limpia, siempre preocupados por el desarrollo sostenible.

Como segunda parte, se da a conocer la industria del corcho, la cual se mantiene a la vanguardia en: investigación, innovación, desarrollo y participación en el compromiso con el medio ambiente.

Como última parte, se mostrará el proceso productivo del corcho de una de las empresas más importantes en esta industria a nivel internacional.

\section{A manera de reflexión:}

¿Alguna vez, se ha preguntado qué hay detrás de un delicioso vino, fuera de los componentes que lleva como es la transformación de la uva, el almacenamiento en barriles de roble para que tome los sabores deseados, así como su proceso de empaque? 
Igualmente, se ha cuestionado, ¿la importancia de seleccionar un buen corcho para los diferentes tipos de vino?, lo cual se constituye en una ventaja competitiva para los productores de vino.

Con el propósito de resolver estas inquietudes, se visitó una de las vinícolas más importantes de Chile, donde se conocieron las diferentes cualidades del vino, la identificación desde la vista, olor y sabor.

Con relación a lo anterior, siguiendo la trayectoria del vino, se adentró al inexplorado mundo del corcho, donde se tuvo el placer de conocer una de las empresas más importantes a nivel mundial en la industria del corcho: Corticeira Amorim, S.G.P.S. S.A, cuya sede principal es en el país Portugal, siendo el principal productor del corcho con una experiencia de más de 150 años.

El corcho cuenta con una importante participación en las diferentes industrias, así como una vital importancia en la industria del vino, la cual debe seleccionar de manera minuciosa la conservación de sus sabores a través de altas tecnologías.

Se trata de conocer este mundo desde un punto de vista diferente, desde su punto de vista de innovación, investigación, biodiversidad y su principal eje en el desarrollo sostenible.

\section{Breve historia del corcho.}

Enric Ribera Gabandé, en artículo sobre los vinos, Revista La Cuina de Catalunya (30 de agosto de 2015), afirma lo siguiente:

Relacionado con los antecedentes históricos del corcho, se cree que el monje francés Dom Pérignon descubridor del champagne, usó por primera vez el tapón de corcho en el año 1.670, posteriormente experimentó con otros materiales que tuvieran la facultad de soportar la presión generada dentro de las botellas. En aquel tiempo se utilizaban tacos de madera, los cuales se envolvían en fibras o lacres para tapar la botella; este tipo de productos no fueron prácticos.

Corcho, Cultura, Naturaleza, en el año 2015 nos cuenta la procedencia del corcho:

Ahora bien, respecto del origen del corcho, se puede afirmar que se obtiene de un árbol que existe desde hace más de mil años, su nombre es el alcornoque (Quercus suber L.), el cual mantiene sus hojas verdes todo el año, de su corteza se extrae el corcho, la cual contiene unas células (suberina) con una característica especial que la hace impenetrable al agua y conserva la temperatura.

Concha y Toro, habla sobre la importancia del corcho para el vino (agosto de 2010):

Es recogido en el Parque Natural de los Alcornocales, tiempo de vida aproximadamente 200 años y se pueden cosechar cada nueve (9) años, su característica principal es el aporte al medio ambiente, ya que es un árbol renovable, su extracción es directamente en la corteza de los árboles, evitando así la tala de árboles. Como anteriormente se mencionó, la corteza está 
compuesta por unas celdas que contienen una sustancia llamada suberina, la cual permite que sea: impenetrable al agua, conserva la temperatura, sea elástico y consciente a la emersión del corcho.

\section{Traspaso de oxígeno.}

Algunas irregularidades son producidas por la porosidad natural del corcho y por los espacios entre la botella y el corcho, éstos son producidos por las lenticelas, y por tanto permiten el traspaso del oxígeno.

Las lenticelas son perforaciones que tienen la superficie de los árboles y permite el paso del oxígeno desde el exterior al interior del árbol, en pocas palabras el corcho no debe tener lenticelas, por el contrario, debe ser largo y liso para ser utilizados en vinos Premium, sin embargo, los corchos con estos orificios pueden usarse en vinos jóvenes.

Por otro lado, los corchos de tipo aglomerado son para consumo de vinos jóvenes.

\section{Procedencia.}

Teniendo en cuenta que el alcornoque tiene hojas verdes durante todo el año, característica que hace que la hoja sea perenne y al mismo tiempo tiene una corteza muy especial de corcho.

Proviene principalmente de Portugal, representa la mayor cantidad de áreas de bosque plantado con un $34 \%$ equivalentes en hectáreas a 736.775, seguido de España, Marruecos, Argelia, Túnez, Francia e Italia. Para un total de 2’139.942 de hectáreas de boques plantados.

En el siguiente cuadro, se muestran las áreas de bosque de corcho en los países productores:

\begin{tabular}{|l|r|c|}
\hline \multicolumn{1}{|c|}{ País } & \multicolumn{1}{c|}{$\begin{array}{c}\text { Áreas } \\
\text { (hectáreas) }\end{array}$} & $\%$ \\
\hline Portugal & 736.775 & 34 \\
\hline España & 574.248 & 27 \\
\hline Marruecos & 383.120 & 18 \\
\hline Argelia & 230.000 & 11 \\
\hline Túnez & 85.771 & 4 \\
\hline Francia & 65.228 & 3 \\
\hline Italia & 64.800 & 3 \\
\hline Total & 2.139 .942 & 100 \\
\hline
\end{tabular}

Tabla 1Países productores

Fuente: CORK (2018) 
El porcentaje anual de la producción de corcho por tonelada se muestra en el siguiente cuadro:

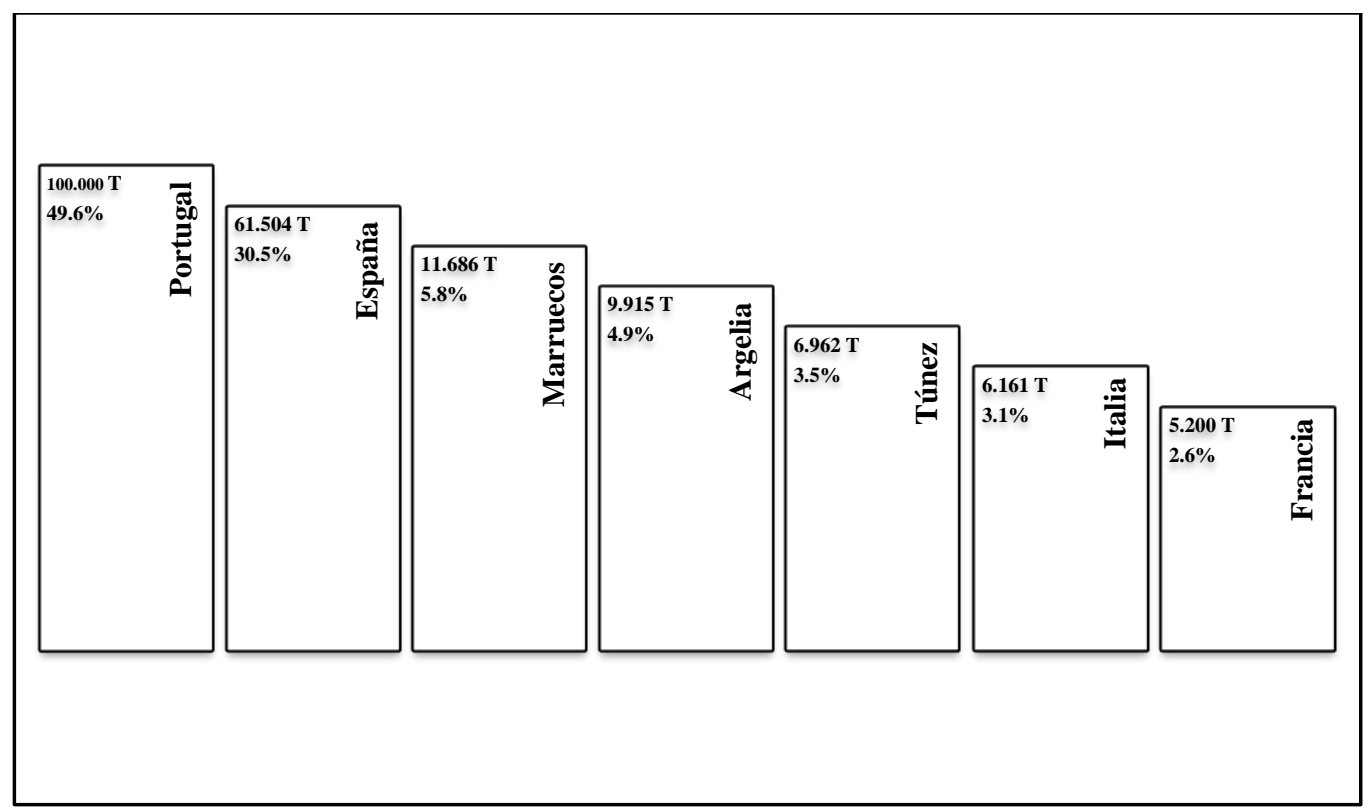

Tabla 1 Producción de corcho en porcentajes anuales

Fuente: FAO (2010)

\section{Producción, Investigación + Desarrollo e Innovación.}

Conozcamos el proceso productivo del corcho, desde su extracción y producción como desarrollo sostenible; así como, los diferentes estudios realizados y la innovación, como una ventaja medioambiental:

\section{Extracción del corcho:}

Victoria del Boca, nos cuenta algo sobre la extracción del corcho:

Se considera que la industria del corcho es de tipo artesanal, ya que el proceso se lleva a cabo en pequeños talleres, los cuales se encuentran ubicados cera a los bosques de alcornoques. Para realizar el descorche se utilizan hachas especiales, incisiones precisas a la corteza con cuidado de no dañar el tronco y luego desprenderla, un solo trabajador puede separar hasta 600 kilos por día, dicho trabajador especializado.

No genera desperdicio alguno, todo es reutilizable, a partir del material aglomerado, el cual tiene múltiples usos: revestimientos de paredes, entre suelos, entre muros, ropa, accesorios de vestir, accesorios de hogar y calzados, entre otros. 


\section{CORTICEIRA AMORIM AÑO 2007 - "Rumbo al Desarrollo Sostenible”.}

Durante el año 2007, Corticeira Amorim, siempre identificada con el desarrollo sostenible, realizó varios estudios, los cuales tenían como meta una producción a través del desarrollo sostenible, a continuación, se dan a conocer:

La producción del corcho, como una oportunidad de desarrollo sostenible de la mano de la innovación y la investigación:

\section{Comparación del impacto medioambiental:}

La globalización mundial enfrenta los devastadores abusos del medio ambiente. Por lo anterior y partiendo del principio que la materia prima forestal es el primordial insumo del negocio, Corticeira Amorim comprometida con el desarrollo sostenible, enfocó sus estrategias de modo global y total hacia la competitividad y la diferenciación en el desarrollando de nuevos productos que armonicen con el medio ambiente y que protejan la naturaleza.

\section{Estudios realizados:}

Análisis del ciclo de vida de los tapones de corcho frente a las cápsulas de aluminio y los tapones de plásticos, midiendo el impacto ambiental.

(Estudio realizado: Pricewaterhouse/Ecobilan-ISO 14040 y 14044)

Estos estudios no contemplaron los impactos medioambientes en el ciclo de vida de los tapones que no son de corcho. En el caso de los tapones de aluminio no se consideraron los impactos medioambientales asociados al proceso productivo de la transformación del aluminio.

En los tapones de plástico, no se tuvo en cuenta el impacto del proceso de transformación de las materias primas (derivadas del petróleo).

Resultados: estudio en botellas de $750 \mathrm{ml}$. Vino consumido en el Reino Unido:

\begin{tabular}{|c|c|c|c|}
\hline \multirow[b]{2}{*}{$\begin{array}{l}\text { Lugar de } \\
\text { producción }\end{array}$} & $\begin{array}{l}\text { Tapón de } \\
\text { corcho }\end{array}$ & $\begin{array}{l}\text { Cápsula } \\
\text { de } \\
\text { aluminio }\end{array}$ & $\begin{array}{l}\text { Tapón de } \\
\text { plástico }\end{array}$ \\
\hline & $\begin{array}{l}\text { Portugal } \\
\text { St. María } \\
\text { de Lamas }\end{array}$ & $\begin{array}{r}\text { Francia } \\
\text { Chalon- } \\
\text { sur- } \\
\text { Saone }\end{array}$ & $\begin{array}{r}\text { Bélgica } \\
\text { Thismister } \\
\text { Clermon }\end{array}$ \\
\hline $\begin{array}{l}\text { Dimensiones } \\
(\mathrm{mm} \times \mathrm{mm})\end{array}$ & $45 \times 24$ & $60 \times 30$ & $43 \times 22$ \\
\hline Peso & 3,5 & 4,6 & 6,2 \\
\hline
\end{tabular}

Tabla 3: Rumbo al Desarrollo Sostenible - Fuente Corticeira Amorim, 2007 
El estudio concluyó que el tapón de corcho presenta ventajas medioambientales frente a los tapones alternativos en los diferentes indicadores.

Los revestimientos de madera emiten entre 2,5 y 4 veces más $\mathrm{CO}_{2}$ que un pavimento de corcho, mientras que las emisiones de $\mathrm{CO}_{2}$ del pavimento vinílico son entre 6,5 y 11 veces superiores.

La innovación: Ventajas medioambientales de los revestimientos de corcho:

La Unidad de Negocio de Revestimiento (BASF), lanzó una nueva generación de revestimiento, a través de la tecnología ecoaglutinante Acrodur, aglutinante a base de agua que reduce el nivel de niveles de emisión con un excelente desempeño técnico.

Productos analizados:

\begin{tabular}{|l|rr|r|r|r|}
\hline Producto & \multicolumn{2}{|l|}{$\begin{array}{l}\text { Revestimientos de } \\
\text { corcho } \\
\text { 100WRT }\end{array}$} & $\begin{array}{l}\text { Revestimiento de } \\
\text { sercho Serie 200 } \\
\text { WRT }\end{array}$ & $\begin{array}{l}\text { Revestimiento } \\
\text { de madera }\end{array}$ & $\begin{array}{l}\text { Pavimento } \\
\text { vinílico } \\
\text { LVT }^{1}\end{array}$ \\
\hline $\begin{array}{l}\text { Dimensiones } \\
(\mathrm{mm})\end{array}$ & $295 \times 905$ & $300 \times 600$ & $1220 \times 190$ & $300 \times 300$ \\
$\begin{array}{l}\text { Espesor } \\
\text { Peso }\left(\mathrm{kg} / \mathrm{m}^{2}\right)\end{array}$ & 10,5 & 4,0 & 13,5 & 3,8 \\
& 8,0 & 2,1 & 10,0 & 3,8 \\
\hline
\end{tabular}

Tabla 4: dimensiones de productos analizados

Fuente: LVT (2016)

Superior eco eficiencia de los revestimientos de suelos de corcho.

El menor consumo de recursos (energía y materias primas).

Menor costo para los clientes finales, en razón a la larga vida útil, los pavimentos de los corchos logran reducir los costos de calefacción, gracias a las propiedades de aislamiento térmico.

Solución gases efecto invernadero, procesos productivos más eficientes, aislamiento térmico proporcionado por el corcho y capacidad de la materia prima renovable de contener $\mathrm{CO}_{2}$.

\section{Certificación forestal.}

Teniendo en cuenta que Corticeira Amorim, no cuenta con su propia reserva de bosques pero que se encuentra comprometida con el impacto forestal, reportó una disminución del $3.4 \%$ en relación con el año anterior. En consecuencia, logró obtener la certificación de sistema de gestión forestal en Portugal. 
En cuanto a los productos forestales, el reconocimiento de la importancia de un Sistema de Gestión Forestal como un interés importante en su certificación traducido en 8.400 nuevas hectáreas del alcornocal portugués por parte del FSC (Consejo de Administración Forestal).

\section{Biodiversidad.}

En cuanto a la iniciativa Business \& Biodiversity celebró en 2007 un acuerdo para la "Valoración y Sostenibilidad del Alcornoque y de la Biodiversidad Asociada". Permite una oportunidad única entre el Gobierno Portugués, las ONGs y el líder mundial de la industria del corcho, reconocimiento en la biodiversidad y en la lucha contra la desertificación y el cambio climático.

Fuente: CORTICEIRA AMORIM - Rumbo al Desarrollo Sostenible - 2007

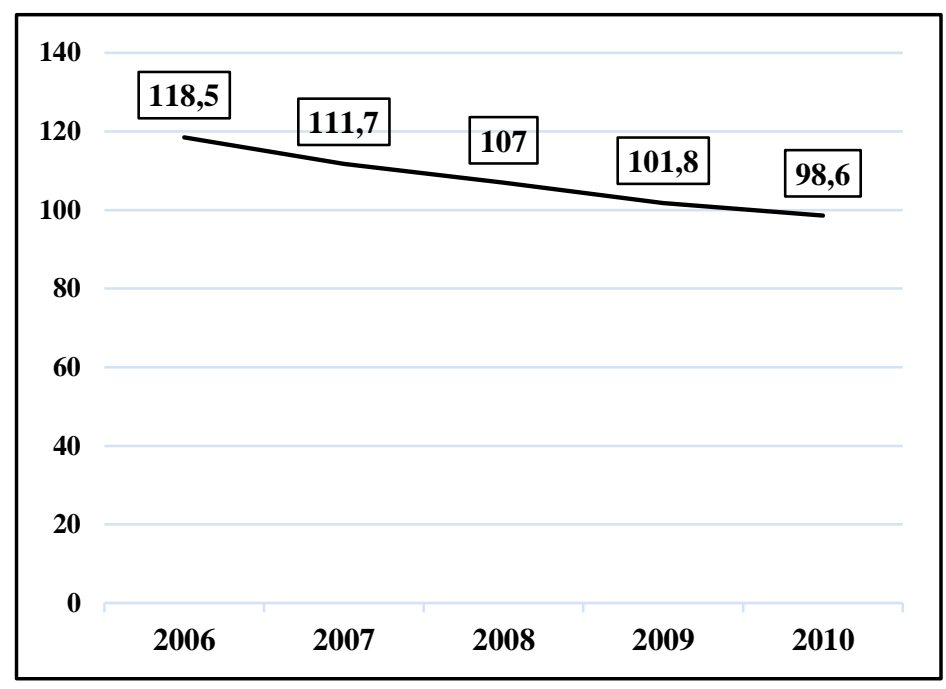

Gráfica 1: innovación hacía el desarrollo sostenible.

Fuente: Corticeira Amorim (2010)

Siguiendo su trayectoria, cuyo principal propósito es el de mantener una producción limpia, a través del desarrollo sostenible, la innovación e investigación, en el año 2010, Amorim, inicia la implementación de un programa de innovación, cuyos objetivos son los siguientes:

Promover cultura organizacional orientada a la innovación + creación de valor.

Plan estructurado de gestión de interfaces: conocimiento de ideas, adaptación organización que permita identificar y capturar oportunidades internas y externas.

Control y evaluación eficaz de sus prácticas de innovación. MEJORA CONTIGUA.

Proyectos más destacados:

Nuevo desarrollo CORKSORB, refuerza la absorción del corcho. 
Creación de un material que permite incorporar las características únicas del corcho a los termoplásticos.

Estudios con el fin de garantizar la interacción del vino del tapón de corcho frente a tapones alternativos.

Solución para impedir la migración de compuestos de los tapones que puedan variar el color en las bebidas blancas.

Desarrollo del 5G. Nuevo sistema de encaje para las tarimas flotantes de la gamma Corkcomfor, permite instalación más rápida y más fácil.

Lanzamiento del CORKwall, producto que rehabilita las fachadas exteriores y paredes interiores, aislante acústico y térmico, que previene la pérdida de energía.

Nuevo tol ayer, garantiza el aislamiento acústico y térmico de las tarimas flotantes y que permite aplicar directamente en las superficies del diseño final del suelo.

Sistema de gestión Forestal FSC.

Durante el año 2010, la empresa reforzó el compromiso con el FSC.

\section{Biodiversidad.}

Corticeira Amorim, viene financiando un servicio gratuito de asesoramiento técnico a productores forestales para identificar y adoptar las mejores prácticas de gestión forestal.

Lanzamiento de la segunda edición del premio de investigación "Valoración del alcornoque y de la biodiversidad asociada".

\section{Calentamiento Global.}

Corticeira Amorim contribuye a combatir el calentamiento global, mediante soluciones en el desarrollo del corcho, a través de la conservación y mantenimiento de las dehesas de alcornoques. En las siguientes tablas se puede evidenciar la disminución de la intensidad carbónica en relación con el año 2006 al año 2010 de un 118,5 a un 98,6 respectivamente.

\section{Toneladas $\mathrm{CO}_{2} / 1$ millón euros de ventas}

\begin{tabular}{|c|c|c|c|c|c|}
\hline & 2006 & 2007 & 2008 & 2009 & 2010 \\
\hline $\begin{array}{l}\text { Emisiones } \\
\text { totales } \mathrm{CO}_{2}(\mathrm{t})\end{array}$ & 52.443 & 50.683 & 50.122 & 42.273 & 45.024 \\
\hline $\begin{array}{l}\text { Ventas (millones } \\
\text { euros) }\end{array}$ & 443 & 454 & 468 & 415 & 457 \\
\hline
\end{tabular}

Tabla 5: Innovación Hacia el Desarrollo Sostenible

Fuente: CORTICEIRA AMORIM, S.G.P.S., S.A. (2010) 


\section{Conclusiones sobre la producción de desarrollo sostenible:}

Aunque el vino no es el producto que más aporta a la economía de Chile como lo pensábamos, es armonioso su espíritu de cultura el acompañarlo en las comidas, dando el ambiente esperado en los diferentes sitios que se conocen, sean alta o medianamente distinguidos. Así mismo, la elegancia que se percibe de estar en este país con su inigualable diversidad de sabores, destinado para cada gusto

Es mágico conocer lo que no era obvio y tiene una gran importancia en lo maravilloso del vino y es el corcho parte primordial de todo este proceso, con el cual, se mantiene vivo cada uno de sus sabores, olores y colores logrando salvaguardar lo que costó tanto tiempo, trabajo y esfuerzo llevar a cabo. Además, el diseño de este corcho lleva consigo la marca de deleitar a sus clientes.

En este proceso de su construcción, que creíamos fácil y simple pero como lo mencionamos en este artículo conlleva muchos pasos y procesos, nos deleitamos al conocer de cerca una de sus empresas principales en este producto:

Corticeira Amorim, la dedicación de sus trabajadores y el crecimiento a base de su experiencia en la organización, haciéndola exaltar como su familia y dando el sitio de importancia en cada uno de los pasos de su elaboración recopilado en algunas fotografías.

\section{Un recorrido por la planta de Corticeira Amorim.}

Como primera medida, las normas de seguridad fueron bastante rigurosas, se suministraron batas desechables, gorros, audífonos y no se podían utilizar ningún elemento metálico que pudiera por accidente afectar el proceso del corcho, el trabajador encargado de la producción dio a conocer el motivo de esta seguridad, ya que cualquier cabello o elemento volátil puede llegar a dañar toda una producción, posteriormente suministró información sobre su proceso productivo, así:

La corteza toma 9 años para ser apto de descortezar sin afectar la corteza, para esta labor se necesitan expertos con una precisión única para evitar el daño de la corteza.

Luego, es puesto en planchas curvas, ligeras y jugosas de la savia del árbol, las cuales se usan según lo refinado de su corte: las más finas para corchos técnico u otros materiales, solo las de mejor calidad, más gruesas y suaves, después de reposar medio año en zonas especiales y de ser sometidas a tratamiento de última generación, serán utilizadas en la elaboración del tapón. (Amorim, 2018, p.3)

\section{Láminas, previo a transformación del corcho.}

Las láminas conformadas por colmenas de células microscópicas de suberina, las cuales están llenas de un gas parecido al aire. Por tal razón, es liviana, impermeable a gases y líquidos, puede ser comprimida, otra característica es su aislante natural a la humedad y al sonido. Su memoria 
elástica hace que se adapte a las variaciones de temperatura y presión.

Es resiste a la fricción, combustión y al deterioro del tiempo y adicionalmente no atrae el polvo. Cabe destacar que es un material muy versátil y que se encuentra a disposición del ser humano. De otro lado, es íntegramente natural, biodegradable, renovable y reciclable.

Por otra parte, se destaca que el alcornoque demora 25 años en ser descorchado por vez primera, sin embargo, a partir del tercer descorche, logra la calidad que requiere para realizar la producción corchos.

Posteriormente, se apilan planchas encima de acero en el hormigón para evitar la contaminación con el suelo. En la separación de las planchas, se seleccionan las de mejor calidad las que se procesaran como tapones.

Existen diferentes clases de tapones, los cuales se clasifican de acuerdo la calidad de las planchas seleccionadas. A continuación, hablaremos de los diferentes tapones:

\section{Tapones naturales.}

Según Amorin (2018) en el proceso de producción del corcho encontramos una variedad que se denomina de "alta gama", para lograrlo es necesario trabajar con planchas naturales que se separan en láminas, posteriormente se perforan por medio de herramientas que facilitan la generación de cilindros, cada uno es un corcho entero, trabajados de manera manual o semiautomática con sumo cuidado y exactitud. Se elaboran aproximadamente 20.000 corchos, los cuales son seleccionados con mucha atención para mantener una armonía entre calidad y cantidad.

Son clasificados de manera mecánica y retratada por avanzados organizadores, los cuales los clasifican de acuerdo con la calidad percibida de manera visual. El material restante no se desperdicia, es utilizado en corchos técnicos. Solo el $25 \%$ es utilizado para corchos naturales.

Luego de la extracción, se toma una muestra importante, la cual es analizada mediante un proceso de cromatografía gaseosa para realizar control de calidad, y de esta manera detectar elementos dañinos, especialmente TCA la "enfermedad del corcho", la cual es tratada con ROSA Evolution (sistema patentando por Amorim).

Todos los corchos deben pasar por este proceso y en caso de detectar la mínima presencia del TCA, se de iniciar su proceso para hacer los ajustes necesarios. Por otra parte, todos los corchos deben pasar por un proceso de destilación a vapor, con el propósito de garantizar alta calidad a los productores de vino, lo que representa una ventaja competitiva para Amorim.

Con el fin de garantizar un acabado limpio y suave a los corchos naturales, éstos son pulidos. Posteriormente, pasan por un proceso de lavado, a través del peróxido de hidrógeno $(\mathrm{H} 2 \mathrm{O} 2)$, y son secados en hornos industriales para ser estabilizados. Su finalidad es evitar que se contaminen de microbios. 
Una vez terminado el proceso, se ratifica que los corchos cumplen con los estándares exigidos por el cliente, luego son marcados, a través de fuego o con tinta, esta tina es avalada por la Food and Drug Administration (FDA), paso seguido son cubiertos con una película suave de silicona o parafina para realizar de manera fácil la tarea de introducir y extraer el corcho en la botella.

El proceso termina, cuando los lotes son empaquetados en sacos de polietileno, aquí se aplica un conservante que se usa generalmente en la industria del vino (SO2) y luego se sellan.

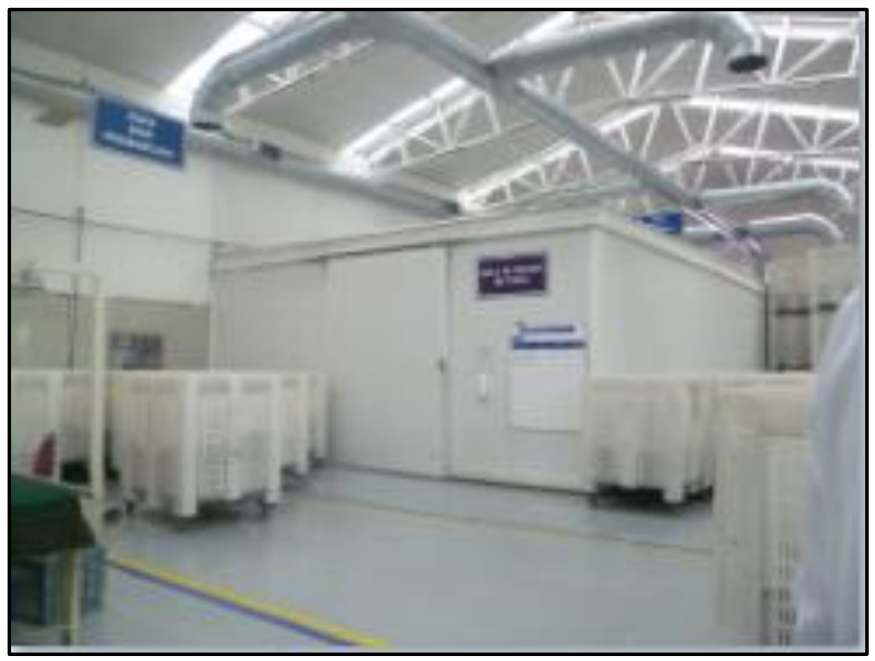

Ilustración 2 Cuarto de corchos Amorin

Fuente; Fotografía tomada en visita a las instalaciones (2018)

\section{Tratamiento y nivel de prevención.}

Su proceso de prevención y tratamiento al más alto nivel permite que las "planchas para los tapones pasen por el cuidado (Amorin) en su proceso, evitando el nivel de humedad y el aprovechamiento de las materias primas para darle paso a otros productos.
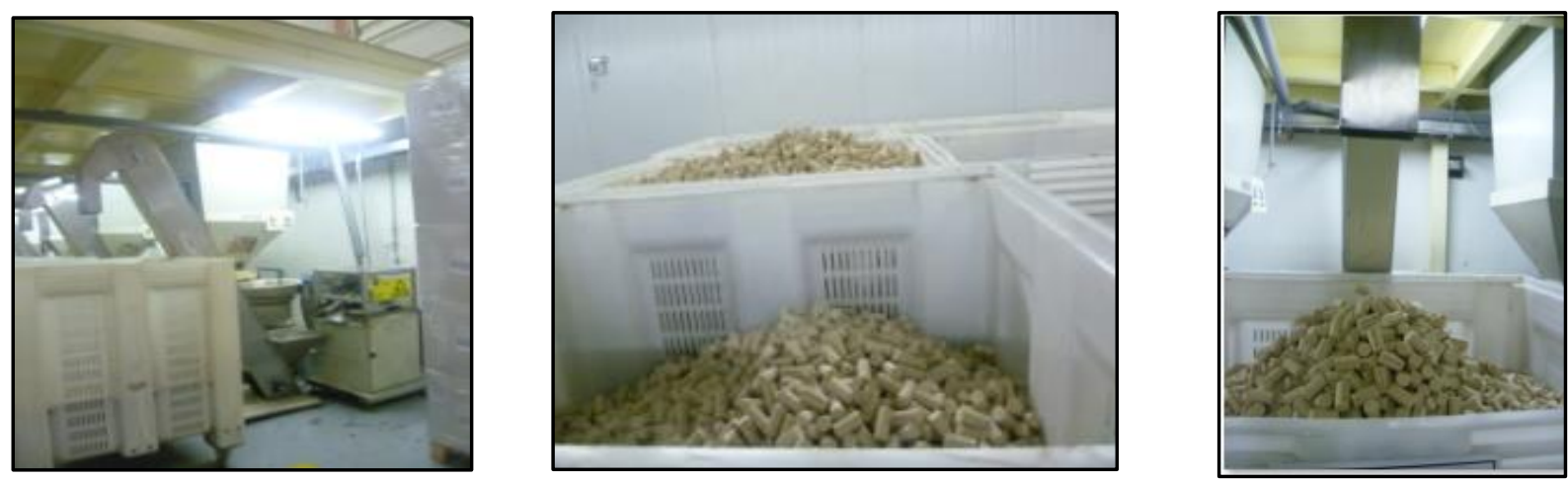

Ilustración 3 almacenamiento de Corchos

Fuente: Las fotografias fueron tomadas en la visita a las instalaciones Corticeira - Amorim, - Santiago de Chile 2018 


\section{Tapones técnicos.}

Un subproducto del corcho natural son los tapones técnicos, los cuales se extraen de las planchas finas o de los corchos naturales, su proceso de cocción es igual al de los corchos naturales.

Con el fin de conseguir unas láminas suaves y uniformes los lados de las planchas se alisan, deben cumplir con grosor de aproximadamente $6,5 \mathrm{~mm}$. Luego se perforan a lo largo del crecimiento con máquinas mandriladoras, éstas ejercen una presión fuerte y pareja en la parte interna del cuello de la botella de vino. Aquí los discos son separados electrónicamente, el disco es la parte del corcho que hace contacto con el vino.

Amorim patentó un proceso de lavado INOS IIß, que bombea agua purificada sin cloro a $70^{\circ} \mathrm{C}$, dicho proceso provoca contracción y dilatación de las células del corcho y obliga a la contaminación a salir. (Amorim, 2018, p.27)

Las aglomeraciones de los corchos técnicos deben cumplir con un proceso de pulverización y filtración, aquí son seleccionados los que midan entre $3 \mathrm{~mm}$ y $7 \mathrm{~mm}$, con el fin de que suministren más fuerza y flexibilidad al corcho. Igualmente, todos los corchos deben atravesar por el proceso ROSA, con el fin de ser destilados.

"Posteriormente, el cuerpo se moldea individualmente o se obtiene por extrusión y se corta a medida. Ambos procesos de aglomeración usan cola aprobada por la FDA". (Amorim, 2018, p.29)

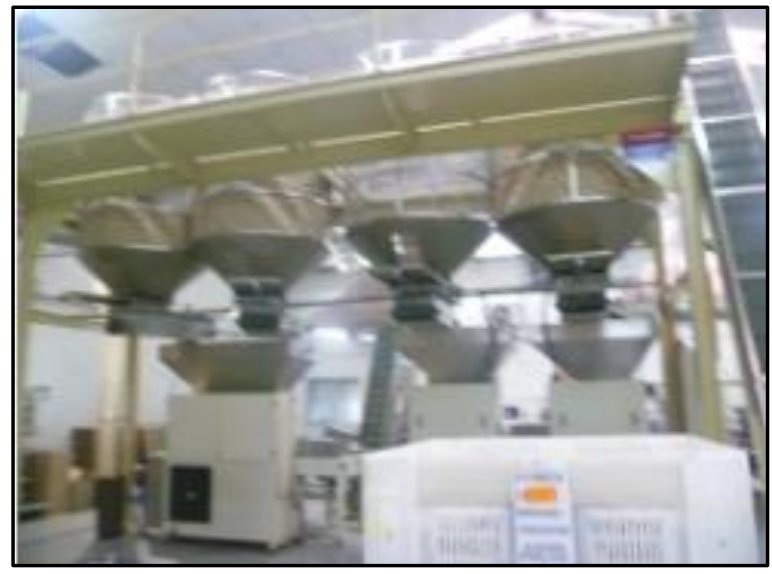

Ilustración 4 : sobre el montaje los tapones, Amorim 2018

Fuente: Las fotografías fueron tomadas en la visita a las instalaciones Corticeira - Amorim, - Santiago de Chile 2018 
El montaje de los tapones se realiza de forma mecánica. Los discos y los cuerpos se introducen a través de silos. Los discos pasan por un equipo de selección mediante cámaras para determinar el lado superior del disco que entrará en contacto con el vino. El otro lado se encola al cuerpo del tapón de corcho. Una vez montado, el tapón se seca en un horno durante una hora antes de ser estabilizado. Los tapones técnicos pasan por un proceso de pulido, lavado y acabado idéntico al de los tapones naturales. (Amorim, 2018, p.30)
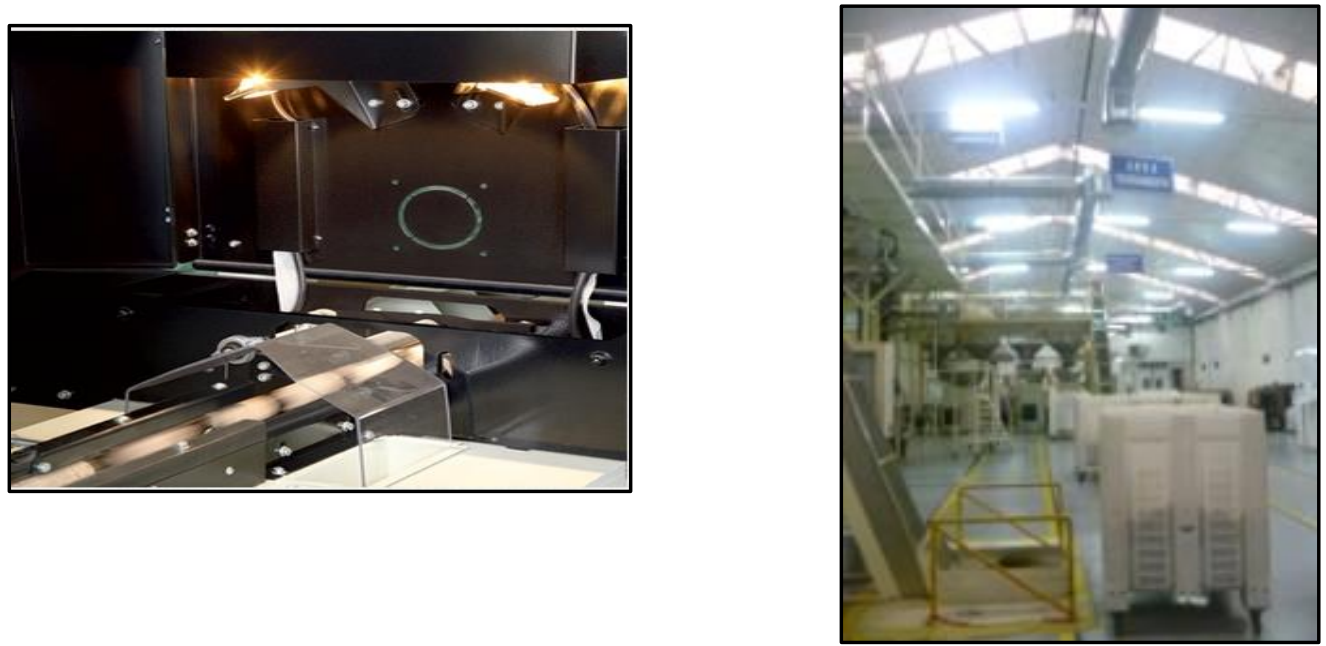

Fotografía tomada en las instalaciones de Amorim, Santiago de Chile, 2018

Completo el proceso productivo de los tapones técnicos, los cuales cumplen una función muy importante en la industria del vino, de aquí se desprenden otros subproductos, es decir, que en la industria del corcho todos los productos son aprovechables, por lo tanto contribuyen con el medio ambiente, su materia prima no produce desperdicios, en razón a que es reutilizada para suplir las necesidades de otras industrias.

De igual manera, el proceso productivo muestra su nivel de innovación y control de calidad, a través del método de análisis en sus productos, al punto que pueden destilar los tapones de corcho, mediante el proceso ROSA, único en el mundo, diseñado y patentado por Corticeira Amorim para combatir el TCA.

Otro motivo para decir que Corticeira Amorin, cuenta con ventajas competitivas que le ofrecen seguridad a través de la calidad de sus productos, no solo en la industria del vino, sino también en las diferentes unidades de negocio que los hace competitivos.

En la siguiente gráfica se observar el Flujo de Producción: 


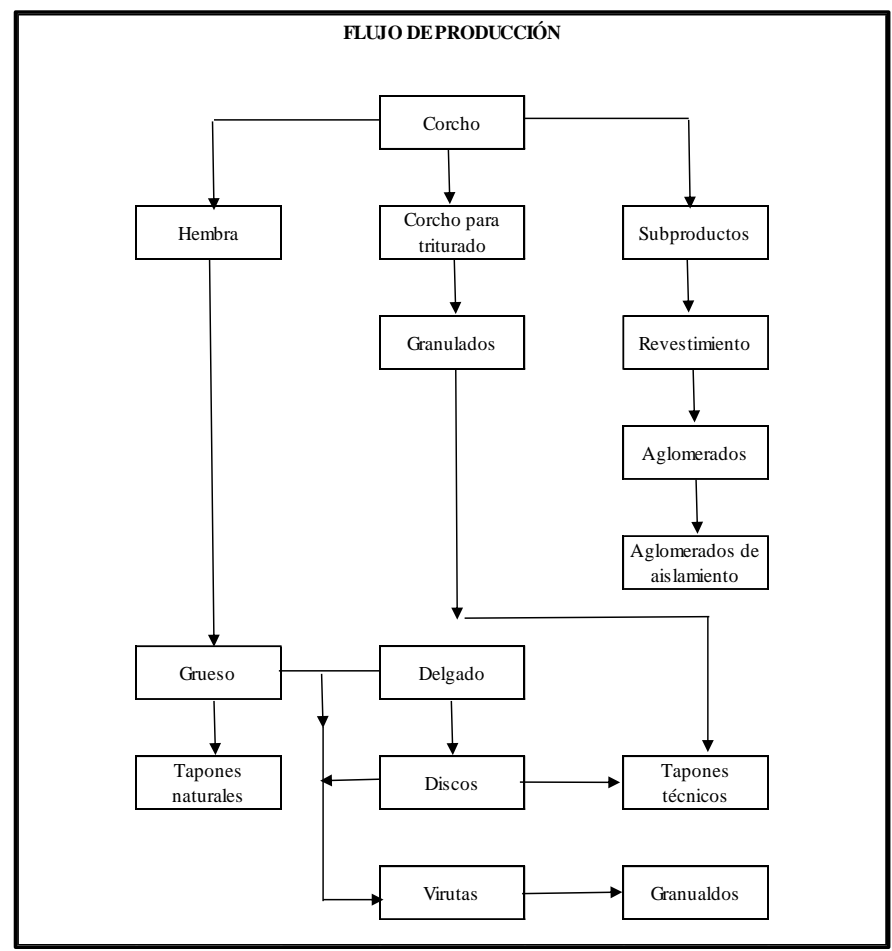

Ilustración 5 Flujo de producción

Fuente Amorin (2018)

Por otra parte, se observa el control de producto no conforme el cual es importante en el proceso del ciclo del producto, con el cual garantizan que, aunque todo no es perfecto se detecta y se maneja.

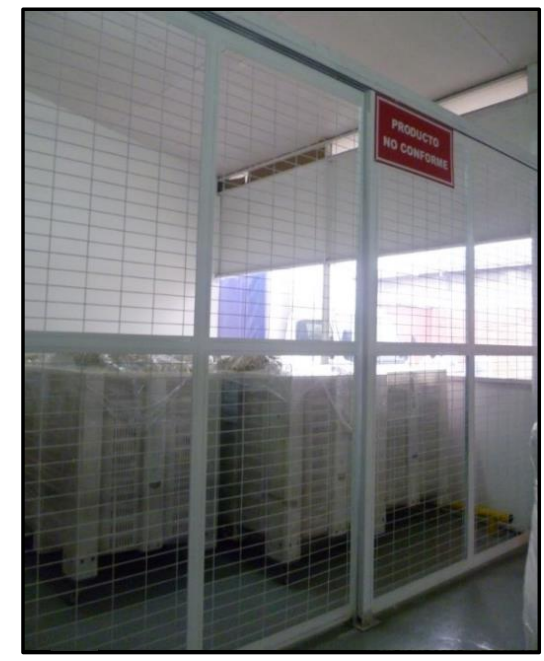

Ilustración 6 Almacenamiento Producto No Conforme_planta de producción Corticeira Amorim. Fuente: Propia (2018) 
Así mismo, existen áreas de investigación y análisis, quienes frecuentemente controlan la calidad del producto y lo más importante la mejora del mismo, frente al mercado y así mismo, identificando oportunidades.

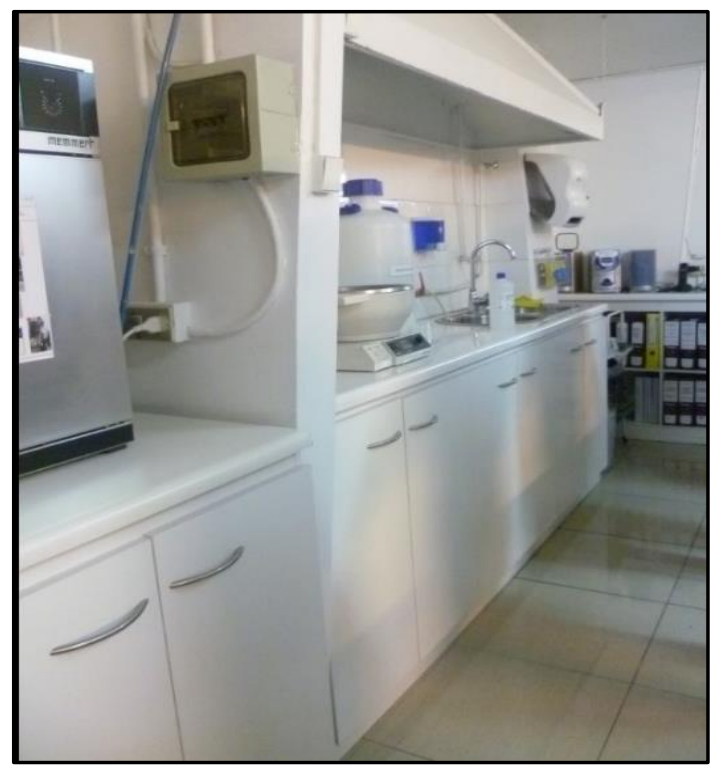

Ilustración 7 Control de Calidad,

Fuente: fotografías Amorim, Santiago de Chile, 2018

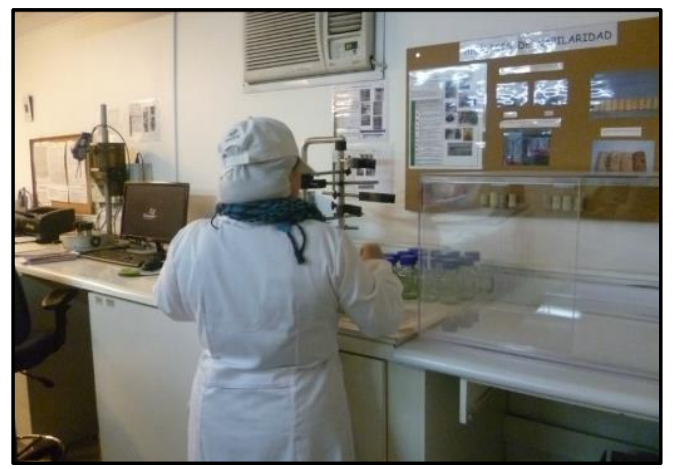

Ilustración 8 Comprometidos con el análisis, investigación e innovación Fuente: Propia 2018

Finalmente, se termina el proceso de producción de los tapones desde sus diferentes usos, existen diferentes tapones, los cuales se mencionan a continuación:

Tapón de corcho natural, alta gama para los mejores vinos.

Tapón Acquamark®, a un costo competitivo.

Tapón Top Series ${ }^{\circledR}$ une la calidad y el prestigio de un tapón de corcho natural al lujo y la unicidad de cada cliente.

Tapón Spark® para champañas y vinos espumosos.

Tapón Twin Top® para champaña. 
Tapón técnico más famoso: Twin Top® Evo, para vinos con notas florales y afrutadas. Tapón Neutrocork ${ }^{\circledR}$, para vinos que presentan cierta complejidad y de consumo rápido (2 años).

Tapón Advance®, para vinos de gran rotación.

Tapón Advance Colors®, bebidas de consumo rápido.

Tapón de corcho aglomerado, para vinos de consumo rápido.

Amorim, cuenta con otra unidad de negocio llamada "Custom made Corks", la cual está destinada para suplir otras industrias, como son: laboratorios, farmacéutica, aceites, artículos decorativos, formas en cristal, productos cosmético, productos para pesca y cocina; así como de productos de arte y alimentos

El recorrido por la planta de producción del corcho demuestra que el potencial de su negocio es el minucioso cuidado en la elaboración de los tapones, con altos estándares de calidad en sus procesos, una producción limpia, donde se puede identificar el aprovechamiento del 100\% de la materia prima, lo cual nos permite afirmar, que es un sector que le suministra una plusvalía al medio ambiente y vive en alianza natural con los fabricantes del vino.

Por su excelente gestión se ha posicionado dentro de los líderes del mercado, a través de su estrategia de verticalización del negocio (año 1962) con el propósito de lograr un liderazgo mundial en la exportación y producción, aprovechamiento de los recursos, su capacidad innovadora e investigativa y teniendo en cuenta como eje principal desarrollo sostenible, en síntesis, es una empresa con sabiduría industrial.

\section{Conclusiones:}

En primer lugar, se puede afirmar que el vino, es el mejor embajador de Chile teniendo en cuenta que, aunque no es el principal producto de este país, es la gran referencia y aporta a su cultura, economía e industria. Por otra parte, las vinícolas más reconocidas por la producción del vino son registradas por su excelente producto; sin embargo, se desconoce el magnífico proceso productivo del corcho, el cual es el mejor amigo del vino, aunque de no ser de excelente calidad podría llegar a ser su peor enemigo.

En segundo lugar, es interesante declarar que la industria del corcho es sostenible, competitiva y sobre todo permite que los productores mantengan una constante mente creativa para competir de manera amplia y ganar la confianza de los productores de vino, a través de una producción limpia, siendo amigables con el medio ambiente a través de recursos renovables y en el aprovechamiento de las materias primas como insumos hacia otras industrias, o en la incursión de nuevas unidades de negocio, con una permanente innovación e investigación lo ubica dentro de los pioneros en su grupo, con altos estándares en los sistemas de gestión.

Por último, se puede asegurar que Corticeira Amorim, se mantiene comprometida con la globalización en un nivel de alta competitividad, a través de sus prácticas en el desarrollo sostenible y el mundo del vino cuenta con garantía de que su sabor perdurará por mucho tiempo. Es una empresa que inició con una idea de negocio y que ha logrado perdurar por más de 150 años, teniendo como principio el desarrollo sostenible, donde no solo involucra el negocio como un interés personal, sino que involucra a todos los grupos de interés, a sus trabajadores, a su 
desarrollo financiero y sostenible, sin afectar el medio ambiente, dejando como legado que se puede producir, haciendo bien las cosas con respeto, armonía y conciencia. 


\section{Referencias bibliográficas:}

Amigos de las bodegas, 2014, la importancia del corcho para la conservación del vino, https://www.amigosdelasbodegas.com/la-importancia-del-corcho-para-el-vino/

Amorim, 2018, Perfecto por Naturaleza, https://www.amorimcork.com/es/corchonatural/materia-prima-y-proceso-productivo/ Amorim, 2018, La Elección Natural, https://www.amorimcork.com/pt/corticeira-amorim/

Banco Central de Chile, 2017, https://si3.bcentral.cl/Siete/secure/cuadros/arboles.aspx

Cata Vino, 2014, La Cultura del Vino como Tapón para el Vino, http://www.catadelvino.com/blog-cata-vino/la-importancia-del-corcho-como-tapon-para-elvino

Chile, Política y Economía, Santander Trade Portal, 2017, Contexto Económico, https://es.portal.santandertrade.com/analizar-mercados/chile/politica-y-economia

Chile Valora, 2017, Mejorando Las Competencias Laborales, https://www.chilevalora.cl/wpcontent/uploads/2017/09/Vitivin\%C3\%ADcola-Publicable-proyecto.pdf

Comisión Nacional de Investigación Científica y Tecnológica, 2007

Concha y Toro, 09/06/2017, Todo Sobre Corchos, https://www.conchaytoro.com/wineblog/todo-sobre-corchos/

Concha y Toro, 2014, La Importancia del Corcho para el Vino, https://www.conchaytoro.com/wine-blog/la-importancia-del- corcho-para-el-vino/

Corcho24.es, SF, Propiedades del Corcho: Térmica y acústica y más, https://corcho24.es/propiedades-del-corcho/

Corticeira Amorim, S.G.PS. S.A., 2018

Corticeira Amorim, Rumbo al Desarrollo Sostenible (2007)_Folleto visita 2018

Corticeira Amorim, S.G.PS. S.A. (2010)_Folleto visita 2018

Diario El Español, 12/01/2017, Cocinillas, Porque las Botellas de Vino Tiene Tapones, https://cocinillas.elespanol.com/2017/01/por-que-las-botellas-de-vino-tienen-tapones-decorcho/

Documento de la Universidad de Chile: Instituto de Estudios Internacionales

Economía Sector Primario, Lourdes Fernández López, SF, El vino mantiene su importancia 
económica...y su valor social, https://jable.ulpgc.es/jable/cgi-

bin/Pandora.exe?fn=commandselect;query=id:0007575793;command=show_pdf

El Mostrador de Mercados, 2017, Exportaciones de Vino Chileno subió 3\% en 2017, con China y Brasil entre las mayores alzas, http://www.elmostrador.cl/mercados/2018/02/07/exportacion-de-vino-chileno-subio-37-en2017-con-china-y-brasil-entre-las-mayores-alzas/

Enric Ribera Gabandé, 30/08/2015, La Cuina de Catalunya, Dom Pérignon no Descubrió El Champagne, http://www.lacuinadecatalunya.com/dom-perignon-no-descubrio-el-champagne/

Joaso Santos Pereira, Miguel Nuno, Bugalho e María de la Concepción (Instituto Superior de Agronomía), 2015APCOR, Asociación Portuguesa del Corcho, Cork-dossier-Medio-Ambiente "Corcho, Cultura, Naturaleza, procedencia del corcho"

Victoria de Bocca, SF, Origen del Corcho, http://www.victoriadebocca.com/espanol/origendel-corcho/ 